\title{
Lithosphere and upper-mantle structure of the southern Baltic Sea estimated from modelling relative sea-level data with glacial isostatic adjustment
}

\author{
H. Steffen ${ }^{1}$, G. Kaufmann ${ }^{2}$, and R. Lampe ${ }^{3}$ \\ ${ }^{1}$ Lantmäteriet, Lantmäterigatan 2c, 80182 Gävle, Sweden \\ ${ }^{2}$ Freie Universität Berlin, Institut für Geologische Wissenschaften, Fachrichtung Geophysik, Malteserstr. 74-100, Haus D, \\ 12249 Berlin, Germany \\ ${ }^{3}$ Ernst-Moritz-Arndt-Universität Greifswald, Institut für Geographie und Geologie, F.-L.-Jahn-Str. 16, 17487 Greifswald, \\ Germany
}

Correspondence to: H. Steffen (holger-soren.steffen@1m.se)

Received: 26 November 2013 - Published in Solid Earth Discuss.: 23 December 2013

Revised: 4 April 2014 - Accepted: 4 April 2014 - Published: 10 June 2014

\begin{abstract}
During the last glacial maximum, a large ice sheet covered Scandinavia, which depressed the earth's surface by several $100 \mathrm{~m}$. In northern central Europe, mass redistribution in the upper mantle led to the development of a peripheral bulge. It has been subsiding since the begin of deglaciation due to the viscoelastic behaviour of the mantle.

We analyse relative sea-level (RSL) data of southern Sweden, Denmark, Germany, Poland and Lithuania to determine the lithospheric thickness and radial mantle viscosity structure for distinct regional RSL subsets. We load a 1-D Maxwell-viscoelastic earth model with a global ice-load history model of the last glaciation. We test two commonly used ice histories, RSES from the Australian National University and ICE-5G from the University of Toronto.

Our results indicate that the lithospheric thickness varies, depending on the ice model used, between 60 and $160 \mathrm{~km}$. The lowest values are found in the Oslo Graben area and the western German Baltic Sea coast. In between, thickness increases by at least $30 \mathrm{~km}$ tracing the Ringk $\varnothing$ bing-Fyn High. In Poland and Lithuania, lithospheric thickness reaches up to $160 \mathrm{~km}$. However, the latter values are not well constrained as the confidence regions are large. Upper-mantle viscosity is found to bracket $[2-7] \times 10^{20} \mathrm{~Pa}$ s when using ICE-5G. Employing RSES much higher values of $2 \times 10^{21} \mathrm{Pas}$ are obtained for the southern Baltic Sea. Further investigations should evaluate whether this ice-model version and/or the
\end{abstract}

RSL data need revision. We confirm that the lower-mantle viscosity in Fennoscandia can only be poorly resolved.

The lithospheric structure inferred from RSES partly supports structural features of regional and global lithosphere models based on thermal or seismological data. While there is agreement in eastern Europe and southwest Sweden, the structure in an area from south of Norway to northern Germany shows large discrepancies for two of the tested lithosphere models. The lithospheric thickness as determined with ICE-5G does not agree with the lithosphere models. Hence, more investigations have to be undertaken to sufficiently determine structures such as the Ringkøbing-Fyn High as seen with seismics with the help of glacial isostatic adjustment modelling.

\section{Introduction}

During the last colder climatic phase with average surface temperatures being about $10^{\circ} \mathrm{C}$ lower than today (Petit et al., 1999), northern Europe - like other parts in the world - was covered by an extensive ice sheet. The mass of this so-called Fennoscandian ice sheet deformed the earth's crust into the mantle, leading to surface depressions of several hundreds of metres underneath the ice. Beyond the ice-covered area, a peripheral bulge developed around the ice sheet due to the bending of the elastic lithosphere outside the ice-covered 
area. This narrow band of $100-200 \mathrm{~km}$ width was uplifted up to a few tens of metres (Steffen and Wu, 2011). During and after the deglaciation phase, the mass redistribution is reversed, forcing uplift of the formerly glaciated areas and subsidence of the peripheral bulge. These changes are, due to the viscoelastic and thus time-delayed behaviour of the mantle, still observable today.

This dynamic response of the earth during glacial cycles is known as glacial isostatic adjustment (GIA). There are several observation methods for this process, and Fennoscandia has turned out to be the key area for GIA studies (e.g. Steffen and $\mathrm{Wu}, 2011$, and references therein). Relative sea-level (RSL) data provide the longest observational data set from all observations, occasionally dating back several thousands of years. They document the movement of coastlines as a consequence of both the water redistribution between oceans and ice sheets and the deformation of the earth's surface that occurred in the past.

RSL data can be employed for the determination of the earth's internal structure, in particular the lithospheric thickness and mantle viscosities (e.g. Steffen and $\mathrm{Wu}, 2011$, and references therein). Often, this is done in formerly glaciated areas, e.g. Fennoscandia, the Barents Sea or the British Isles. As an example, Steffen and Kaufmann (2005) subdivided the Fennoscandian RSL data set into RSL data located in the centre around the Baltic Sea and coastal data mainly along the Norwegian coast. They found clear differences in the earth's structure of the two regions. Vink et al. (2007) subdivided a RSL data set of the southern North Sea into three distinct regional subsets. A regional variation of the lithospheric thickness as well as regionally differing isostatic subsidence curves were determined.

The earth structure beneath northern Europe derived from GIA data can be summarized as follows: in Fennoscandia, the lithosphere is laterally varying with a thick root of more than $200 \mathrm{~km}$ in central-east Fennoscandia, becoming thinner towards the west (Steffen and Wu, 2011). Southwest Sweden is predicted to have a lithospheric thickness of about $100 \mathrm{~km}$, and the German North Sea coast as well as the Norwegian Atlantic coast of about $80 \mathrm{~km}$ (Vink et al., 2007; Steffen and $\mathrm{Wu}, 2011)$. Note that we use the term lithosphere to refer to the strong outer shell of the earth composed of the crust and upper part of the mantle, which both have a purely elastic rheology on the GIA timescale.

Below the lithosphere, investigations have found uppermantle viscosity to be between $10^{20}$ and $10^{21} \mathrm{Pas}$ (Steffen and $\mathrm{Wu}, 2011)$. The latest results calculated from different data are in the range [3-8] $\times 10^{20} \mathrm{Pas}$. The viscosity increases towards the lower mantle (Steffen and Kaufmann, 2005). The lower-mantle viscosity is assumed to be around 1-2 orders of magnitude higher. Its determination, however, is complicated, as the resolving power of all data in Fennoscandia is too low to resolve more accurate values for the lower mantle (Steffen and Wu, 2011).
The values above have mainly been determined with spherically symmetric models using Maxwell rheology. However, other rheologies such as composite rheology (van der Wal et al., 2013) or models with laterally varying lithospheric thickness and/or mantle viscosities (Wu et al., 2005; Steffen et al., 2006; Wang et al., 2008; van der Wal et al., 2013; Wu et al., 2013) can also fit the observations in Fennoscandia reasonably well.

The lithosphere determined in GIA studies should be comparable to results from other studies, e.g. seismological studies. However, there are different geophysical definitions of the lithosphere depending on the method used for its determination. There are rheological, petrological, elastic, thermal, electrical and seismic definitions. It is beyond the scope of this paper to discuss individual definitions or their determination in detail, or the relation of one lithosphere definition to another. We therefore refer the interested reader to Tesauro et al. (2009), Eaton et al. (2009) and Artemieva (2009) for a detailed overview. But it has been noted that some of the definitions should coincide, such as the thermal definition and the seismological one (Tesauro et al., 2009). Eaton et al. (2009) define the lithosphere as "a rheological term referring to the strong outer shell of the earth composed of the crust and upper part of the mantle; also called a mechanical boundary layer". The seismological lithosphere is generally the highvelocity outer layer of the earth, approximately coincident with the lithosphere as a rheological term, which typically overlies a low-velocity zone (Eaton et al., 2009). The thermal lithosphere is defined by a depth to a constant isotherm or by the depth of the intersection of a continental geotherm either with a mantle adiabat or with a temperature close to mantle solidus (Artemieva, 2009). We will see that the lithospheric structure in northern Europe as derived with GIA modelling and outlined above, partly agrees with thermal and seismological studies on the lithosphere on a broad scale, but only in terms of lateral variation and not in an exact match of thicknesses.

The purpose of this study is to determine the earth's structure underneath the southern Baltic Sea with special attention given to the lateral variation of the lithosphere. We use RSL data that have emerged mainly in recent years. They are subdivided in regional subsets similar to the studies by Lambeck et al. (1998) and Vink et al. (2007) to derive radial profiles of the earth for five different regions of the southern Baltic Sea. The best-fitting models allow us to analyse the isostatic behaviour of each region, to highlight the lateral structure and to describe the peripheral bulge in northern Central Europe. We do not aim to investigate the presence of the asthenosphere in this area. Seismic tomographic imaging and a few GIA studies (e.g. Fjeldskaar, 1994) have indicated such an area of lower viscosity in western Fennoscandia (Steffen and Kaufmann, 2005). Unfortunately, the RSL data in the southern Baltic Sea cannot be used to accurately determine parameters for the asthenosphere as their time and depth range is small, see discussion in the next section. As an additional 
exercise, we compare the lithospheric thickness as derived in regional subsets to three lithospheric thickness models available to us.

In Sect. 2, we describe the RSL data used. This is followed by an overview of the modelling technique and the ice models implemented in this study (Sect. 3). Results are presented in Sect. 4 and discussed in Sect. 5. This includes a comparison to lithosphere models available to us. Finally, we summarize our main findings in Sect. 6.

\section{Relative sea-level data}

In the past decades mostly basal peat layers (sensu Lange and Menke, 1967) found in sediment cores were used to reconstruct the postglacial sea-level rise along the southern and western Baltic coast. However, these sea-level indicators, often scattered over larger areas, may have experienced different vertical movements due to isostasy and/or compaction and thus are compromised by large uncertainties in many respects. More recently, new sampling, positioning and dating techniques have allowed the detection of archaeological underwater finds such as settlement refuse, boats, fish weirs and fire places, or drowned in situ tree stumps (Tauber, 2007; Lübke et al., 2011). Such finds provide numerous samples for a distinct site and a specific elevation relative to modern sea level. Other approaches use a set of isolation basins or coastal mires to trace the sea-level variation over a longer period in a very limited area (Yu et al., 2004; Lampe et al., 2011). Such investigations allow the construction of sea-level curves owing to better resolution and minor altitude errors and thus higher precision. They provide an excellent base to test different ice-load history models and earth models as well.

For this study we use published data sets from Denmark (Great Belt and Halsskov Fjord: Christensen et al., 1997), northeastern Germany (Schleswig-Holstein: Winn et al., 1986; Jakobsen, 2004; Mecklenburg-Vorpommern: Lampe et al., 2007; Hoffmann et al., 2009; Poland: Uścinowicz, 2003 and a few data from Lithuania: Curonian Lagoon and adjacent areas: Bitinas et al., 2000, 2002). A common feature of the investigated regions is that the postglacial sea-level rise did not start until the transgressing ocean inundated the Danish Great Belt and invaded the Baltic Basin. Age determinations of the earliest marine influence in the southern Baltic therefore lie between 9.4 and $8.0 \mathrm{kacalBP}$ (Hofmann and Winn, 2000; Rößler et al., 2011; Bennike et al., 2004). Because the maximum depth of the Danish Great Belt amounts to $25 \mathrm{~m}$ below sea level, the rising ocean could not invade the Baltic Basin before it inundated this threshold and thus the sea-level change cannot be traced to greater depths. In coastal regions the Pleistocene relief further restricts the depth where the former sea level can be determined.

Therefore, the lowest sea-level indicators used in the study come from offshore areas in the Great Belt and Bay of Kiel, while all other indicators are from near-coastal on- and off- shore areas that are located at much lesser depths. Mostly, the data used belong to larger data sets compiled by archaeological, palaeoecological or geological investigations. From these sets data were chosen which are evaluated as reliably related to the former sea level, considering the kind of dated material and probability of relocation, sedimentary facies, accuracy of altitude determination and age-depth relations in the entire data set.

In addition to these new data for the southern Baltic Sea coast, we investigate RSL data in the southwestern part of Fennoscandia that were used by Steffen and Kaufmann (2005) and Schmitt et al. (2009). We group these data into five regional subsets according to dominant structures visible in the regional geology (Scheck-Wenderoth et al., 2005) and crust-mantle boundary (Dèzes and Ziegler, 2002), see our additional remarks on each subset below.

The first covers the Oslo Graben and the eastern part of the Norwegian-Danish Basin (Fig. 1). It contains 77 data from northern Denmark (Limfjord) and the Oslo Fjord. Lambeck et al. (1998) used a subset for the Oslo Fjord only while the Limfjord data were included in a Danish subset together with data from the Great Belt. We will see that both regions, Limfjord and Oslo Fjord, can be combined into one subset. The second subset includes 44 data from southwest (SW) Sweden that were used by Lambeck et al. (1998) in a subset for SW Sweden as well. In addition, 12 archaeological data from dated Hensbacka sites around the city of Gothenburg as described and used in Schmitt et al. (2009) are added resulting in a total of 56 data for this data set, which is located east of the Teisseyre-Tornquist Zone. The third subset, called Fyn, consists of 128 indicators from the Great Belt and northeastern Germany, but east of Rostock. These data are located within the Rinkøping-Fyn High and extend the area further east almost parallel to the former ice margin. The fourth subset contains 65 data of the bays of Kiel and Lübeck along the western coast of the German Baltic Sea. This area is part of the North German Basin. As there are RSL data which are at the border of the third and fourth subset, we test the influence of these data on the determined best-fitting earth model for each subset. These data are located at Rostock (yellow dots in Fig. 1), Körkwitz (light blue) and the Darss Peninsula (dark blue). As we test all three locations in each subset, this results in four different subset of "Fyn" and "bays of Kiel and Lübeck". The fifth subset encompasses 31 indicators from Poland and Lithuania. These data are found east of the Teisseyre-Tornquist Zone.

Figure 1 shows the spatial and temporal distribution of the data sets. One can clearly distinguish the characteristics of each data set. SW Sweden and the samples of the Oslo Fjord highlight land uplift over the last 15000 years and thus are typical examples of near-field data. The Limfjord index points as well as the other data sets trace the sea-level rise in the last 12000 years, here in conjunction with isostatic subsidence of the forebulge, and therefore illustrate the typical behaviour of far-field data. We also see that the vertical range 

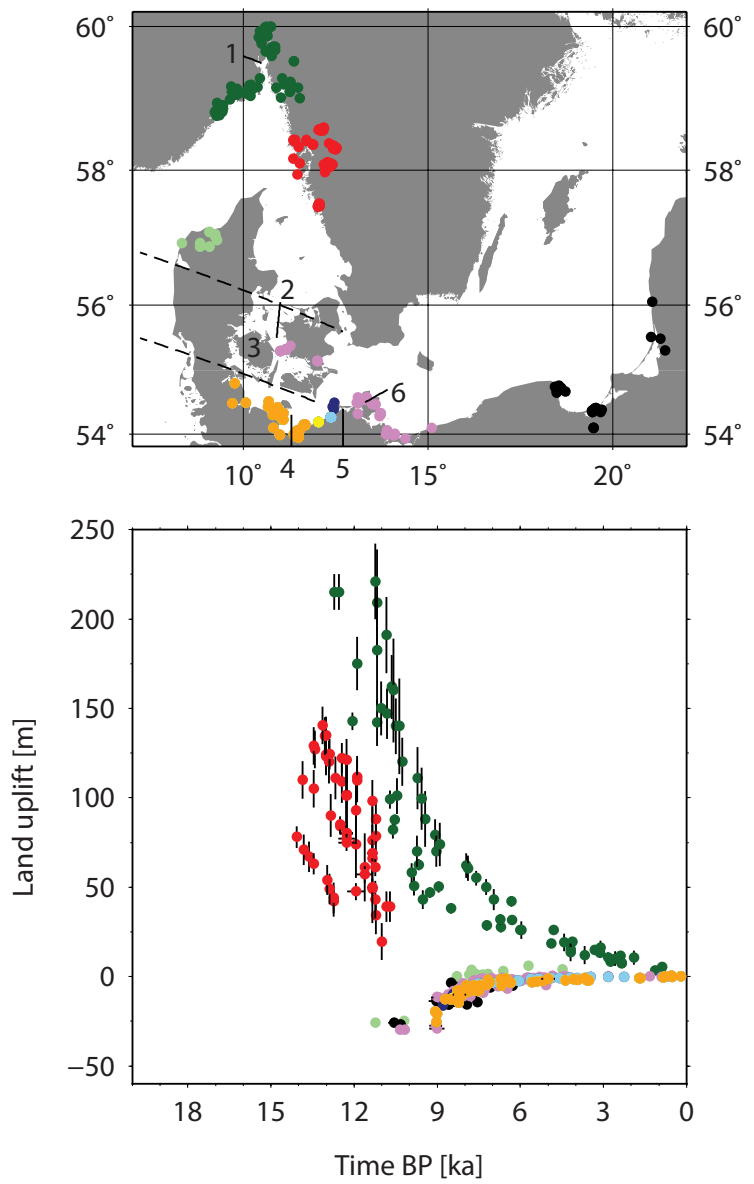

Figure 1. Spatial and temporal distribution of relative sea-level data used in this study. Colours indicate five regional subsets: (I) Southwest Sweden (red), (II) Oslo Graben (dark and light green for Oslo Fjord and Limfjord, respectively), (III) Fyn with Great Belt, Rügen, Usedom (violet), Darss Peninsula (dark blue) and Körkwitz (light blue), (IV) bays of Kiel and Lübeck (orange) and Rostock (yellow), (V) Poland and Lithuania (black). Data uncertainties are indicated by vertical error bars. Geographical information: 1 Oslo Fjord; 2 Great Belt; 3 Fyn; 4 Bay of Lübeck; 5 Darss Peninsula; 6 Rügen. Dashed lines mark the location of the Rinkøping-Fyn High.

of near-field data, here more than $200 \mathrm{~m}$, is much larger than that of the far-field data, which has a range of less than $30 \mathrm{~m}$. The main sea-level change visible in the latter data happens before $7 \mathrm{ka} \mathrm{BP}$. After that, the change is in the metre range.

\section{Modelling}

\subsection{Earth models}

The modelling is undertaken with the software package ICEAGE (Kaufmann, 2004), which was successfully used in earlier GIA studies (e.g. Steffen and Kaufmann, 2005; Vink et al., 2007; Steffen et al., 2010). We briefly summarize the main characteristics and methods only, and refer the reader to Steffen and Kaufmann (2005) for more information.

We employ a spherically symmetric (1-D), compressible, Maxwell-viscoelastic earth model having three layers to be varied; lithospheric thickness, upper- and lower-mantle viscosity. The depth of the boundary between upper and lower mantle is set to $670 \mathrm{~km}$. An inviscid earth's core is set as lower boundary. The viscosity is kept constant within a layer. Elastic parameters are taken from the Preliminary Reference Earth Model (PREM Dziewonski and Anderson, 1981). Lithospheric thickness is varied between 60 and $160 \mathrm{~km}$, upper-mantle viscosity between $10^{19}$ and $4 \times 10^{21} \mathrm{~Pa} \mathrm{~s}$, and lower-mantle viscosity between $10^{21}$ and $10^{23} \mathrm{Pas}$. Based on former investigations (e.g. Steffen and Kaufmann, 2005; Vink et al., 2007) these values cover plausible values for three-layer models well.

We follow the pseudo-spectral approach described in Mitrovica et al. (1994) and Mitrovica and Milne (1998) for the calculation of relative sea levels with our models. It is an iterative procedure in the spectral domain with a spherical harmonic expansion up to degree 192, which solves the sealevel equation (Farrell and Clark, 1976) for a rotating earth. Relative sea levels are calculated for $1089(11 \times 11 \times 9)$ different so-called three-layer earth models which are then compared to our regional RSL data sets based on a least-squares misfit

$\chi=\sqrt{\frac{1}{n} \sum_{i=1}^{n}\left(\frac{o_{i}-p_{i}\left(a_{j}\right)}{\Delta o_{i}}\right)^{2}}$,

with $n$ the number of observations, $o_{i}$ the observed RSL, $p_{i}\left(a_{j}\right)$ the predicted RSL for a specific earth model $a_{j}$, and $\Delta o_{i}$ the error of the observed RSL. The lowest value of $\chi$ relates to the best-fitting earth model $a_{\mathrm{b}}$ out of the 1089 provided. In addition, we analyse the model confidence within the observational errors by calculating the confidence parameter

$\psi=\sqrt{\frac{1}{n} \sum_{i=1}^{n}\left(\frac{p_{i}\left(a_{\mathrm{b}}\right)-p_{i}\left(a_{j}\right)}{\Delta o_{i}}\right)^{2}}$

of the predicted RSL for the best-fitting earth model $p_{i}\left(a_{\mathrm{b}}\right)$ to all other earth models. We show the $1 \sigma$ and $2 \sigma$ uncertainty for models that obey $\psi \leq 1$ and $1<\psi \leq 2$, respectively, of the best-fitting earth model.

\subsection{Ice models}

We apply two different global ice models as load on the earth models. First, as in Steffen and Kaufmann (2005) and Vink et al. (2007), we use the model RSES provided by Kurt Lambeck (Research School of Earth Sciences, Australian National University) (see e.g. Lambeck et al., 1998). It combines the extent and the melting history from different separate ice models around the world. It is an updated version 
of the one presented in Lambeck et al. (1998). The other global ice model is the commonly used ICE-5G ice history (Peltier, 2004). Both RSES and ICE-5G belong to the type of ice models which are constrained by solid-earth models. Hence, best-fitting models usually tend to converge to a radial profile of specific lithospheric thickness and several viscosity layers as used in the ice-model generation. This is especially the case when the same observational data are used in an investigation. In our case, we test a large set of RSL data that have not been used to generate the respective ice models. This may either imply modifications for the ice model if the best-fitting earth model is different, or may shed a light into lateral lithosphere and mantle viscosity variations if the ice model is assumed to be correct. RSES is associated with a 1$D$ earth model that has a lithospheric thickness of $65-85 \mathrm{~km}$, an upper-mantle viscosity of $3-4 \times 10^{20} \mathrm{Pas}$ and a lowermantle viscosity about one order of magnitude larger than the upper mantle. ICE-5G's underlying earth model, called VM2, has a lithospheric thickness of $90 \mathrm{~km}$, and then several viscoelastic layers in the mantle. The average viscosities in the upper and lower mantle are about $6 \times 10^{20} \mathrm{Pas}$ and $2 \times 10^{21} \mathrm{~Pa}$ s, respectively.

We exemplarily show the extent of the Fennoscandian ice sheet at Last Glacial Maximum of the two models in Fig. 2. There are distinct differences in collapse history, ice height and extent of the models, such as the bridge between Fennoscandia and the British Isles. The ice-sheet maximum is located over the Gulf of Bothnia and central Sweden, with more ice in ICE-5G than RSES. Such differences between the ice models will consequently produce different patterns of rebound in the modelling.

\section{Results}

We start presentation of the results with a discussion of the best-fitting three-layer earth models (Table 1) for each ice model and regional RSL data set, which includes a brief presentation of results of the different groupings of sea-level data. We calculated the best-fitting earth model for two subsets of the Oslo Graben, the Oslo Fjord and Limfjord (see Table 1). We find almost the same best-fitting earth model for each RSL data subset, and thus combination of Oslo Fjord and Limfjord RSL data is possible. For the grouping of RSL data either in the Fyn or bays of Kiel and Lübeck subset we provide the results of four different combinations. For both ice models, we consider the combination with Rostock data in the bays of Kiel and Lübeck subset as best (Table 1). There is almost no change in the best-fitting earth model parameters for the Fyn subset using RSES, but the misfit gets worse the more data are moved to the other subset. The other subset (bays of Kiel and Lübeck) has the same best-fitting earth model parameters with and without the Rostock data set, but the misfit is better when including the Rostock data. Assigning more easterly located RSL data, of Körkwitz and

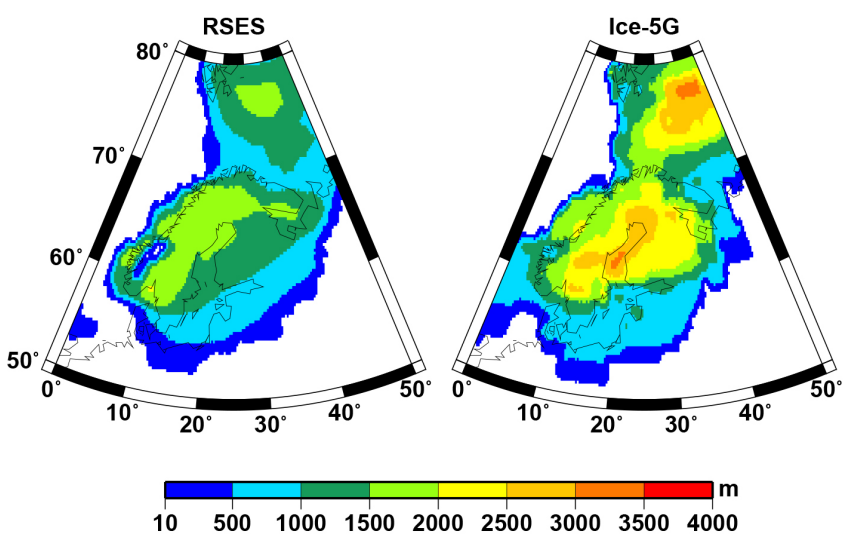

Figure 2. Ice extent at Last Glacial Maximum in Fennoscandia from global ice models (a) RSES (Lambeck et al., 1998) and (b) ICE-5G (Peltier, 2004).

Darss Peninsula, from the Fyn subset to this data set, the earth model parameters change abruptly and the misfit gets worse. Using ICE-5G, there is also a remarkable change in the earth model parameters if RSL data from Körkwitz and Darss Peninsula are moved from one subset to the other. As the misfit gets worse for Fyn when moving more data, and the misfit does not significantly change for the bays of Kiel and Lübeck subset, we use combination (2) in Table 1 in the discussion below.

Both ice models yield mainly similar earth structures for each region: a variation in lithospheric thickness from lower values along the Norwegian coast to higher values towards the Fennoscandian craton, and an increase in mantle viscosity from the upper to the lower mantle. However, distinct differences can be found, when comparing the results for the two ice models. While RSES shows a prominent increase in lithospheric thickness from west to east, thickness as determined with ICE-5G shows only a small increase with the highest value for Fyn. Both the Oslo Graben as well as the bays of Kiel and Lübeck are characterized by an at most $60 \mathrm{~km}$ thick lithosphere for both ice models. As $60 \mathrm{~km}$ is the lowermost tested value in our investigation, thicknesses lower than $60 \mathrm{~km}$ are also possible. In between, the Fyn subset yields a higher thickness of 90 (RSES) to $100 \mathrm{~km}$ (ICE5G). SW Sweden reaches a higher thickness than the Oslo Graben, however, here the values of the two ice models diverge with $90 \mathrm{~km}$ for ICE-5G and $130 \mathrm{~km}$ for RSES. Towards Poland and Lithuania the thickness increases up to $160 \mathrm{~km}$ for RSES, but drops to $80 \mathrm{~km}$ for ICE-5G. Thus, thickness decreases from SW Sweden and Fyn to the southeastern Baltic Sea for ICE-5G, but increases for RSES. However, we note that the misfit for both ice models for the Polish data is much worse although the confidence areas are smaller than for other areas. 
Table 1. Best-fitting three-layer 1-D earth models with RSES and ICE-5G ice-load history, respectively, as derived for each regional RSL data subset. Values in parentheses show the $\sigma_{1}$ range for each model parameter. If no parentheses appear, the $\sigma_{1}$ range encompasses the best-fitting model only. $H_{1}$ lithospheric thickness, $\eta_{\mathrm{UM}}$ upper-mantle viscosity, $\eta_{\mathrm{LM}}$ lower-mantle viscosity, $\chi$ misfit.

\begin{tabular}{|c|c|c|c|c|}
\hline Region & $\begin{array}{r}H_{1} \\
\text { in } \mathrm{km}\end{array}$ & $\begin{array}{r}\eta_{\mathrm{UM}} \\
\text { in } 10^{20} \mathrm{~Pa} \mathrm{~s}\end{array}$ & in $10^{22} \mathrm{~Pa} \mathrm{~s}$ & $\chi$ \\
\hline \multicolumn{5}{|l|}{ RSES } \\
\hline SW Sweden & $130(100-160)$ & $4(3-10)$ & $0.1(0.1-1)$ & 1.18 \\
\hline Oslo Graben & $60(60-70)$ & 2 & $4(0.4-10)$ & 1.58 \\
\hline Oslo Fjord & $60(60-90)$ & 2 & $4(0.4-10)$ & 1.61 \\
\hline Limfjord & $60(60-70)$ & $1(0.5-2)$ & $0.2(0.2-10)$ & 1.13 \\
\hline Fyn $^{1}$ & $90(70-150)$ & $20(7-20)$ & $10(0.7-10)$ & 3.88 \\
\hline $\mathrm{Fyn}^{2}$ & $90(70-150)$ & $20(7-20)$ & $10(0.7-10)$ & 3.91 \\
\hline Fyn $^{3}$ & $90(70-140)$ & $20(7-20)$ & $10(0.7-10)$ & 4.17 \\
\hline $\mathrm{Fyn}^{4}$ & $100(80-160)$ & $20(7-20)$ & $10(1-10)$ & 4.18 \\
\hline Bays of Kiel and Lübeck ${ }^{1}$ & $60(60-150)$ & 20 & $2(2-3)$ & 1.92 \\
\hline Bays of Kiel and Lübeck ${ }^{2}$ & $60(60-150)$ & 20 & $2(2-3)$ & 1.84 \\
\hline Bays of Kiel and Lübeck ${ }^{3}$ & $110(60-150)$ & $20(7-20)$ & $2(0.3-3)$ & 1.97 \\
\hline Bays of Kiel and Lübeck ${ }^{4}$ & $160(120-160)$ & 20 & $4(3-7)$ & 2.01 \\
\hline Polish Baltic Sea & $160(120-160)$ & 20 & $10(7-10)$ & 5.70 \\
\hline \multicolumn{5}{|l|}{ ICE-5G } \\
\hline SW Sweden & $90(60-140)$ & $2(0.6-2)$ & $0.1(0.1-10)$ & 0.87 \\
\hline Oslo Graben & $60(60-70)$ & 2 & $0.4(0.3-0.9)$ & 2.19 \\
\hline Oslo Fjord & $70(60-100)$ & 2 & $1(0.4-10)$ & 1.44 \\
\hline Limfjord & $60(60-80)$ & $0.7(0.3-1)$ & $0.1(0.1-0.2)$ & 1.82 \\
\hline Fyn ${ }^{1}$ & $100(90-110)$ & 2 & 0.1 & 3.19 \\
\hline $\mathrm{Fyn}^{2}$ & $100(90-110)$ & 2 & 0.1 & 3.25 \\
\hline Fyn $^{3}$ & $80(70-90)$ & $4(4-5)$ & $7(4-10)$ & 3.47 \\
\hline Fyn ${ }^{4}$ & $80(70-90)$ & $4(4-5)$ & $7(7-10)$ & 3.48 \\
\hline Bays of Kiel and Lübeck ${ }^{1}$ & $60(60-120)$ & $7(6-10)$ & $0.7(0.3-1)$ & 1.95 \\
\hline Bays of Kiel and Lübeck ${ }^{2}$ & $60(60-70)$ & 4 & $4(2-10)$ & 1.95 \\
\hline Bays of Kiel and Lübeck ${ }^{3}$ & $100(70-140)$ & 2 & 0.1 & 1.90 \\
\hline Bays of Kiel and Lübeck ${ }^{4}$ & $100(70-140)$ & 2 & 0.1 & 1.91 \\
\hline Polish Baltic Sea & 80 & $7(6-7)$ & $7(6-9)$ & 5.04 \\
\hline
\end{tabular}

${ }^{1}$ Initial RSL data subsets of Fyn and Bays of Kiel and Lübeck.

${ }^{2}$ RSL data from Rostock (yellow dots in Fig. 1) are moved from Fyn ${ }^{1}$ to Bays of Kiel and Lübeck ${ }^{1}$.

${ }^{3}$ RSL data from Rostock and Körkwitz (yellow and light blue dots in Fig. 1) are moved from Fyn ${ }^{1}$ to Bays of Kiel and Lübeck ${ }^{1}$.

${ }^{4}$ RSL data from Rostock, Körkwitz and Darss Peninsula (yellow, light and dark blue dots in Fig. 1) are moved from Fyn ${ }^{1}$ to Bays of Kiel and Lübeck ${ }^{1}$.

Pronounced differences exist for the upper-mantle viscosity. While for ICE-5G only small variances between [27] $\times 10^{20} \mathrm{Pas}$ appear for the five investigated regions, the viscosity as determined with RSES varies by one order of magnitude with quite high upper-mantle viscosities of $2 \times 10^{21} \mathrm{~Pa}$ s for southern Baltic Sea RSL data. In SW Sweden and Oslo Graben the viscosity values are comparable to those of ICE-5G. Lower-mantle viscosity also shows a wide range of values; however, it has already been often noted that lower-mantle viscosity cannot be well determined with Fennoscandian RSL data due to their low resolving power to such great depths. Lower-mantle viscosity is generally higher than the upper-mantle viscosity. For SW Sweden, this statement needs to be further evaluated as the lower-mantle viscosity is at the lower bound of our investigation area. A closer look at the $1 \sigma$ range and the misfit maps (Fig. 3) shows that the lithospheric thickness and the upper-mantle viscosity in the Oslo Graben are quite well determined, while lowermantle viscosity can be varied over a larger range, but would still give reasonable fits to the RSL data. In contrast, RSL data from SW Sweden highlight a larger variation of the three parameters. With the RSES ice model lithospheric thickness may range from 100 to $160 \mathrm{~km}$ and more and upper-mantle viscosity from [3-10] $\times 10^{20} \mathrm{~Pa}$ s. Using ICE-5G, this range is smaller, but lithospheric thickness can also reach higher values, providing an overlap to possible thicknesses as determined with RSES. 


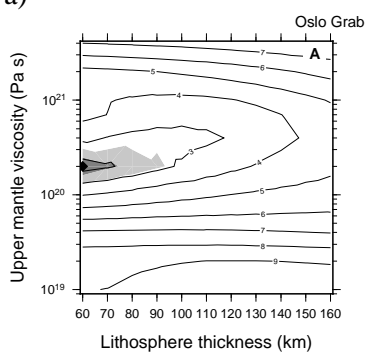

b)

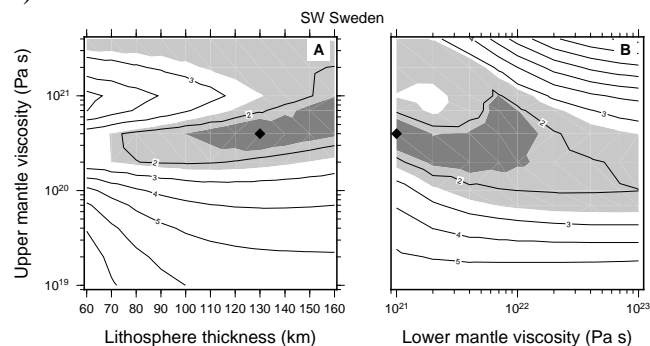

c)

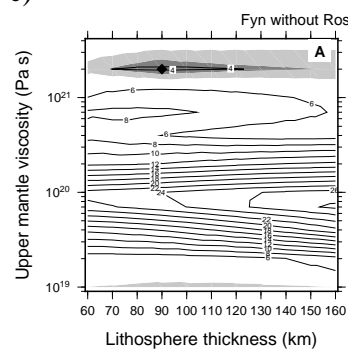

d)

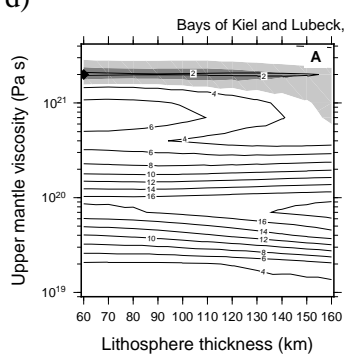

e)

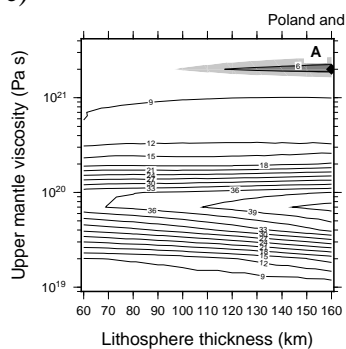

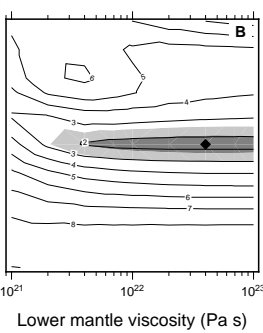

Lower mantle viscosity $(\mathrm{Pa} \mathrm{s})$

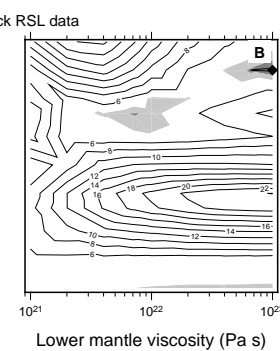

Rostock RSL data

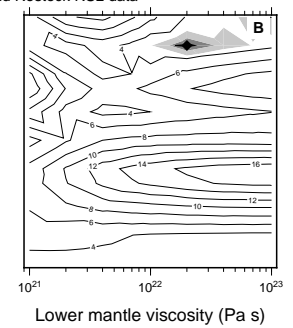

Lower mantle viscosity ( $\mathrm{Pa} \mathrm{s})$

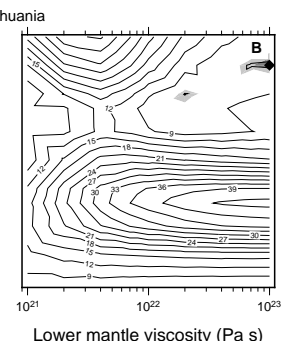

f)

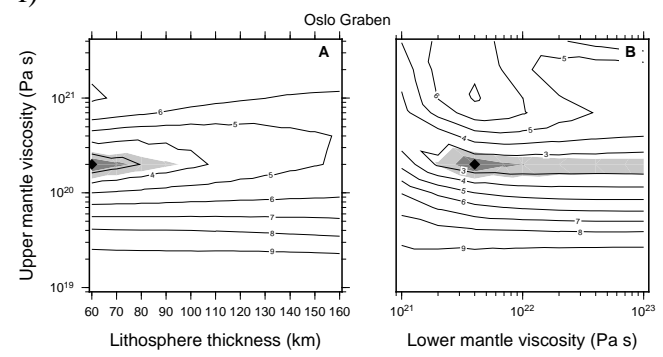

g)

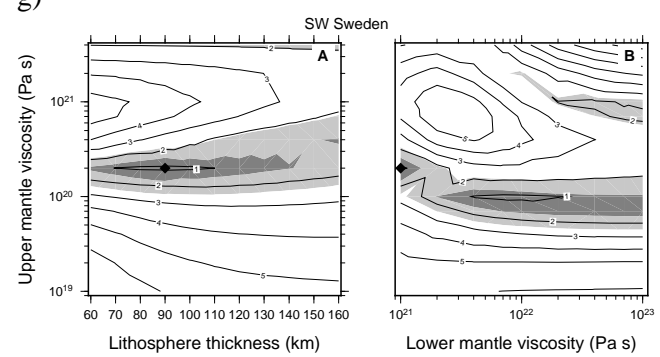

h)

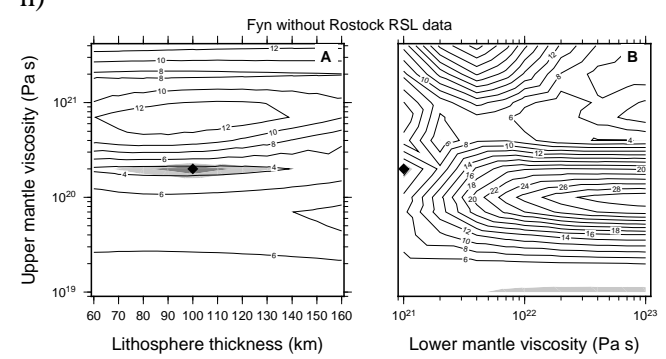

i)

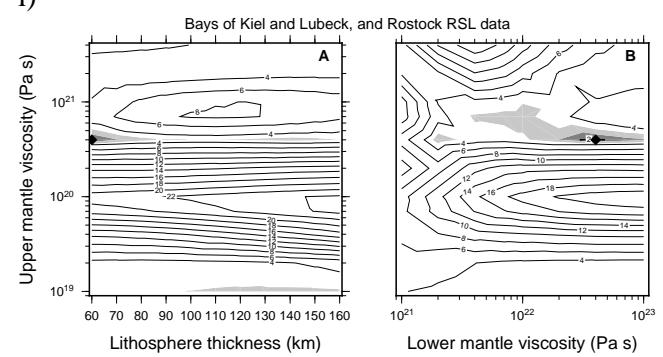

j)

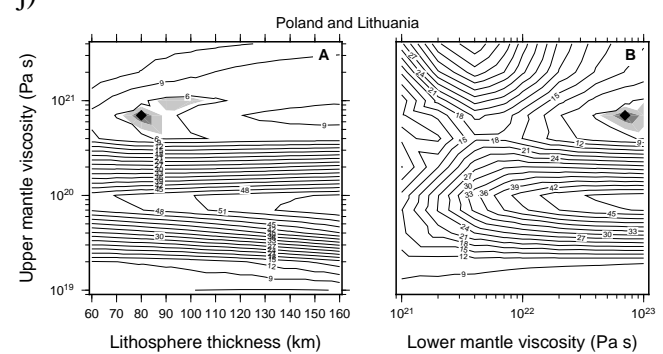

Figure 3. Misfit for ice models RSES (a-e) and ICE-5G (f-j), three-layer earth model and different data sets. Panel A: the misfit map as a function of lithospheric thickness and upper-mantle viscosity for a fixed lower-mantle viscosity according to the best-fitting earth model, see Table 1. Panel B: the misfit map as a function of upper- and lower-mantle viscosities according to the best-fitting earth model for a fixed lithospheric thickness, see Table 1. (a, f) Misfit map for Oslo Graben RSL data (light and dark green dots in Fig. 1). (b, g) Misfit map for SW Sweden RSL data (red dots in Fig. 1). (c, h) Misfit map for Fyn without Rostock RSL data (violet, dark and light blue dots in Fig. 1). (d, i) Misfit map for bays of Kiel and Lübeck and Rostock RSL data (orange and yellow dots in Fig. 1). (e, j) Misfit map for Polish and Lithuanian RSL data (black dots in Fig. 1). The best three-layer earth model is marked with a diamond, the light and dark shadings indicate the confidence regions $\psi \leq 1$ and $1<\psi \leq 2$, respectively. 
For Fyn as well as the bays of Kiel and Lübeck the $1 \sigma$ ranges for the viscosities become much narrower than for SW Sweden. Only lithospheric thickness as determined with RSES may be varied over almost the whole tested parameter range. These two data sets as well as that of SW Sweden show the feature of bifurcation in the misfit maps of lithospheric thickness vs. upper-mantle viscosity. There are two regions of high misfits, one at about $10^{21} \mathrm{Pas}$ and thinner lithospheric thicknesses, and another one at about $10^{20} \mathrm{~Pa} \mathrm{~s}$ and lower covering the whole thickness range. This lower bound and the "island" at $10^{21} \mathrm{~Pa}$ s seem to force the bestfitting model to adopt upper-mantle viscosity values either of [2-7] $\times 10^{20} \mathrm{~Pa}$ s or of $2 \times 10^{21} \mathrm{~Pa}$ s and larger. Lithospheric thickness is not strongly bounded for these two areas of low fits. While ICE-5G prefers the lower upper-mantle viscosity area, RSES tends to higher viscosities. Although the $1 \sigma$ range for the RSES results does not cover the lower uppermantle viscosity range, new deeper and older RSL data and an updated ice model may help shift the results to similar values as determined with ICE-5G.

Another interesting behaviour is that lower-mantle viscosity appears to be, except for SW Sweden, clearly determined. This also holds for the Polish and Lithuanian data. Instead, the island at $10^{21} \mathrm{Pas}$ for upper-mantle viscosity does not appear and lithospheric thickness is better determined (especially for ICE-5G) than for the other regions.

\section{Discussion}

In the previous section we derived bounds for lithospheric thickness and upper- and lower-mantle viscosity for the different regions. We now take closer look at the fitted RSL data. While the locations Oslo Graben and SW Sweden are mainly near-field data with a large time and height/depth range, the other three regional subsets contain far-field data of younger age and smaller depth ranges, i.e. there is only a window of about 4000 years where relative sea levels change by more than $30 \mathrm{~m}$. Thus, it is challenging to identify the best-fitting modelled sea-level curve within the given error bars of the samples out of a large range of possible curves, despite the large number of samples within each subset. The determination of the best-fitting model can be much better achieved for Oslo Graben and SW Sweden. Here, we also note that the clear determination is much better for Oslo Graben as it contains a non-monotonic RSL change with rising and falling sea levels. We can only speculate for the reason of the poorer misfit to the Polish and Lithuanian data. It may be the RSL data themselves, which may be affected by unknown tectonic behaviour or subsidence, imperfections in the ice model, or a combination of both.

Further evaluation of our results is enabled by comparison of calculated sea-level curves from the best-fitting regional earth models to RSL data used. Figure 4 presents sea-level curves at eight selected locations. In the Oslo Fjord and in
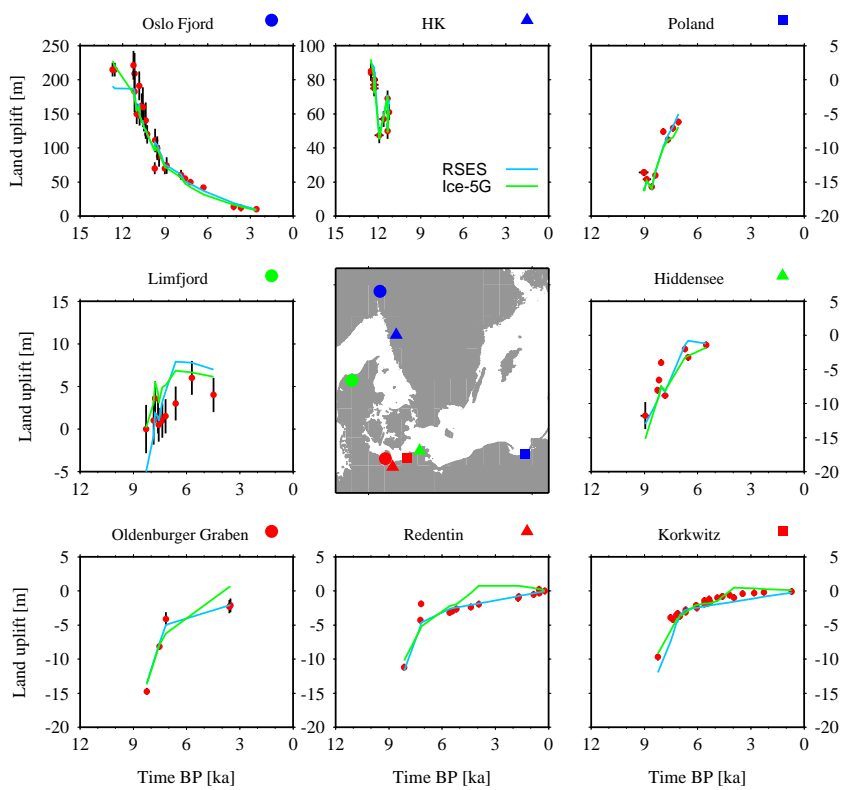

Figure 4. Comparison of RSL data (red dots) at selected locations to sea-level curves as calculated with the best earth model for a respective region and ice model RSES (Lambeck et al., 1998, blue) and ICE-5G (Peltier, 2004, green).

SW Sweden (HK, the archaeological data from Hensbacka culture sites), there is a very good fit between observations and the modelled curves. The RSL data from Limfjord in northern Denmark are not fitted well, but one has to note that there is only small variation of about $5 \mathrm{~m}$ in 5000 years in this data set, which is hard to trace for the model. Along the German Baltic Sea coast, this variation is much larger and thus better fits can be achieved. In Hiddensee both RSES and ICE$5 \mathrm{G}$ ice models result in a good match of the sea-level data, but partly outside the given error bars of the RSL data. In the Oldenburger Graben and Redentin, the RSES ice model traces the RSL data better than ICE-5G, while in Körkwitz the ICE-5G ice model performs better than RSES. In Poland both ice models predict the sea-level rise well. Our comparison shows that although good fits are achieved in some areas, each ice model cannot perfectly fit all data, and some sea-level curves as predicted by the models lie outside the error bars of the observations. Errors in the ice model affect the behaviour of calculated sea-level curves and may lead to a worse misfit, which eventually alters the confidence ranges in Fig. 3. This does not necessarily mean that another earth model would be preferred, but the RSL curve of this earthice model combination is disarranged.

We can compare our results to a former investigation by Lambeck et al. (1998), where the authors already used Fennoscandian RSL data divided into several subregions. However, data from the German, Polish and Lithuanian Baltic Sea coast were not used by Lambeck et al. (1998). In the southwest, RSL data were therefore grouped into these 
Table 2. Overview of three-layer 1-D earth models derived for regional RSL data subsets in the southern Baltic Sea. $H_{1}$ lithospheric thickness, $\eta_{\mathrm{UM}}$ upper-mantle viscosity, $\eta_{\mathrm{LM}}$ lower-mantle viscosity, $\chi$ misfit. ${ }^{*}$ This regional result from Lambeck et al. (1998) contains additional RSL data that were considered to be less satisfactory by Lambeck et al. (1998).

\begin{tabular}{|c|c|c|c|c|c|}
\hline Region & Reference & $\begin{array}{l}\text { Ice } \\
\text { model }\end{array}$ & $\begin{array}{r}H_{1} \\
\text { in } \mathrm{km}\end{array}$ & $\begin{array}{r}\eta_{\mathrm{UM}} \\
\text { in } 10^{20} \mathrm{~Pa} \mathrm{~s}\end{array}$ & in $10^{22} \mathrm{Pas}$ \\
\hline \multirow[t]{3}{*}{ SW Sweden } & this study & RSES & 130 & 4 & 0.1 \\
\hline & this study & ICE-5G & 90 & 2 & 0.1 \\
\hline & Lambeck et al. (1998) & RSES & 50 & 2.5 & 3 \\
\hline * & Lambeck et al. (1998) & RSES & 80 & 1 & 1 \\
\hline \multirow[t]{3}{*}{ Oslo Fjord } & this study & RSES & 60 & 2 & 4 \\
\hline & this study & ICE-5G & 70 & 2 & 1 \\
\hline & Lambeck et al. (1998) & RSES & 80 & 1.5 & 3 \\
\hline \multirow[t]{2}{*}{ Fyn } & this study & RSES & 90 & 20 & 10 \\
\hline & this study & ICE-5G & 100 & 2 & 0.1 \\
\hline (Denmark) & Lambeck et al. (1998) & RSES & 150 & 4 & 3 \\
\hline
\end{tabular}

three subsets with available data: Oslo Fjord, SW Sweden and Denmark. This choice is similar to our study, but the SW Sweden data set from Lambeck et al. (1998) did not contain RSL data from the Hensbacka sites and their Danish data set contained data from the Great Belt and the Limfjord. For Oslo Fjord, the authors found a $80 \mathrm{~km}$ thick lithosphere and an upper-mantle viscosity of $1.5 \times 10^{20} \mathrm{~Pa}$ with an older version of the RSES ice model (Table 2). In SW Sweden lithospheric thickness of $50 \mathrm{~km}$ thickness was $30 \mathrm{~km}$ thinner than that of Oslo Fjord. Upper-mantle viscosity is here slightly higher at $2.5 \times 10^{20} \mathrm{~Pa}$ s. Higher values were found in Denmark. Lithospheric thickness was determined to be $150 \mathrm{~km}$ and upper-mantle viscosity with $4 \times 10^{20} \mathrm{~Pa}$ s. While these results confirm the thicker lithosphere in Denmark/Rinkøping-Fyn High as well as the upper-mantle viscosities of our study, the differences between SW Sweden and the Oslo Fjord are large both in the lithospheric thickness estimate and also in the structural implications. These differences can be explained due to our slightly different grouping, the new data in the SW Sweden subset and the usage of an updated version of RSES that was available to us.

We note in this regard that Kaufmann and Wu (2002) showed that if the ice-load history is known, then it is only possible to accurately estimate lateral changes in lithospheric thickness with 1-D earth models and regional RSL data subsets if there is no lateral change in mantle viscosity below the lithosphere. Otherwise the inferred lateral variations in lithospheric thickness can only be estimated qualitatively. This condition is not met with our RSES ice-load history and thus these results have to be cautiously interpreted. ICE-5G shows smaller variations in upper-mantle viscosity for each region than RSES; therefore, these results are more reliable in view of the findings by Kaufmann and Wu (2002). However, the results from ICE-5G do not agree with seismological results, which show large increase in lithospheric thickness towards the east.

To further evaluate this, we therefore turn to the lithosphere models derived from seismological data and compare them to our results. Gregersen et al. (2002) provided a NE-SW profile from southern Sweden to central Germany based on P-wave velocity perturbation. The generalized profile shows a $300 \mathrm{~km}$ thick lithosphere northeast of the Teisseyre-Tornquist Zone, but we note that the lower boundary cannot be clearly defined due to the relatively high velocities in the upper mantle. Therefore, the lithosphere might be thinner than $300 \mathrm{~km}$. The lithospheric thickness then decreases to about $125 \mathrm{~km}$ between the Rinkøping-Fyn High and the Teisseyre-Tornquist Zone in Denmark, and about $80 \mathrm{~km}$ southwest of the Rinkøping-Fyn High in Germany.

Tesauro et al. (2009) showed a map of thermal lithospheric thickness in Europe south of $60^{\circ} \mathrm{N}$ latitude. The model is based on the inversion of a tomography model of Koulakov et al. (2009) and was provided to us in a $0.25 \times 0.25$ degree grid. In southern Sweden, they find a thickness exceeding $180 \mathrm{~km}$ (Fig. 5a, isolines). The thickness then decreases to about $120 \mathrm{~km}$ in northeastern Germany. In the southern North Sea, they find an average of about $135 \mathrm{~km}$ for Belgium and about $110 \mathrm{~km}$ for the Netherlands and northwest Germany. A comparison with receiver function data mirrored the lateral variation (Tesauro et al., 2009), and visual comparison with newer S-receiver function results (Geissler et al., 2010) supports the results as well. The British Isles have varying thicknesses between 100 and $180 \mathrm{~km}$.

Hamza and Vieira (2012) developed a $2 \times 2$ degree global distribution map of the thermal lithospheric thickness based on global data sets for heat flow and crustal structure. In southern Sweden, lithospheric thickness is found to be between 170 and $210 \mathrm{~km}$ (Fig. 5b, isolines). Similar values arise for the German Baltic Sea coast and Denmark. The southern North Sea has a lithosphere of about 160 to $170 \mathrm{~km}$ thickness. 

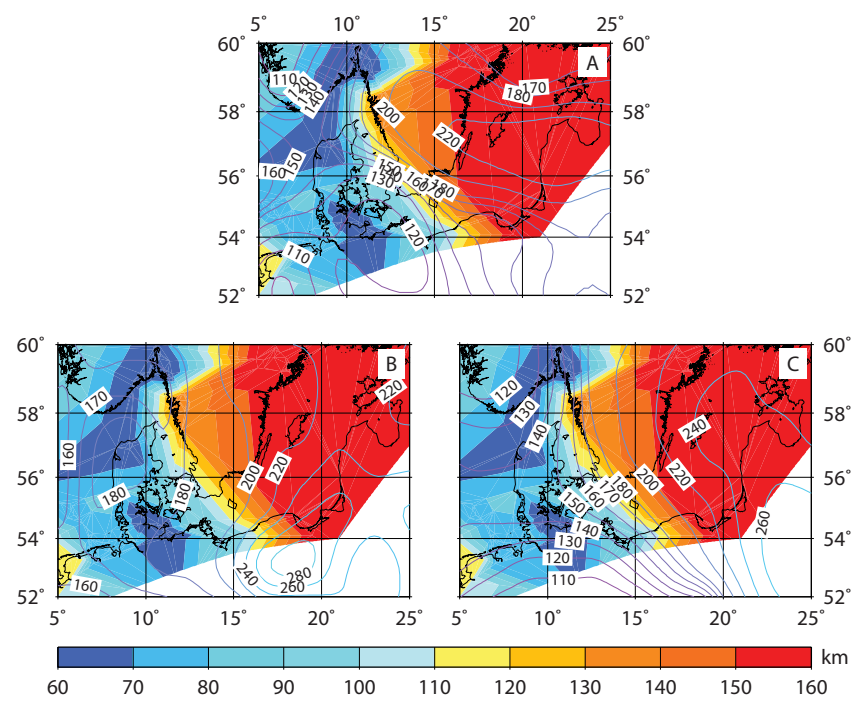

Figure 5. Comparison of calculated regional lithospheric thickness variations with the RSES ice model (filled contour maps) to seismically and thermally derived lithospheric thicknesses (solid lines) by (A) Tesauro et al. (2009), (B) Hamza and Vieira (2012) and (C) Priestley and McKenzie (2013). Contour maps are drawn with the GMT pscontour function.

Recently, Priestley and McKenzie (2013) introduced a $2 \times 2$ degree seismologically determined lithosphere model that also includes thermal information. They combined a surface wave tomography model with temperature (ocean and continents) and pressure (continents) estimates to generate shear-wave velocity estimates. These estimates and a description of their relaxation behaviour at high temperatures is then used to infer the lithospheric thickness. In the southern Baltic Sea area, there are two major structural features (Fig. 5c, isolines). First, lithospheric thickness decreases from $260 \mathrm{~km}$ in the east to $110-120 \mathrm{~km}$ in the west. The gradient is almost constant, but slightly steeper in SW Sweden. Second, from western central Denmark towards the North Sea, an area encompassing the Rinkøping-Fyn High, lithospheric thickness remains at an almost constant level of about $140 \mathrm{~km}$. To the north and south it drops to about $110 \mathrm{~km}$.

Figure 5 shows our results for the best lithospheric thickness estimates with the RSES ice model as coloured maps, with the additional estimates from Steffen and Kaufmann (2005) for Fennoscandia and from Vink et al. (2007) for the southern North Sea to give a more complete overview on GIA-inferred lithospheric thickness. We do not compare our ICE-5G results as (i) they do not show the pronounced thickness increase to the east and (ii) Steffen and Kaufmann (2005) and Vink et al. (2007) did not provide results for this ice model which would allow a comparison in the North Sea and central Fennoscandia. The GIA-inferred lithospheric thickness map is drawn using the GMT pscontour function (Wessel and Smith, 1998) by assigning the lithospheric thickness values of the best-fitting earth model for each region to the coordinates of each RSL data sample location. The results of Tesauro et al. (2009, A), Hamza and Vieira $(2012$, B) and Priestley and McKenzie (2013, C) are overlain with contour lines. In the south and east of the area shown no results exist for the GIA-inferred lithospheric thickness.

In general, the seismically and thermally inferred lithospheric thickness values do not show a good match to our GIA-model results. All these models show lithospheric thicknesses of at least $110 \mathrm{~km}$ in the area under investigation. Also, their maximum values exceed $200 \mathrm{~km}$ considerably. However, we note that these three lithosphere models also do not show a good fit to each other either, except for the general increase from west to east. The thicker lithospheres of the seismological and/or thermal models is due to the fact that a different timescale is addressed. Seismological results are related to observations and processes of seconds to minutes, while the GIA-inferred lithosphere is related to a process of $100 \mathrm{ka}$. Nonetheless, relative differences should agree.

The thickness according to Hamza and Vieira (2012) has a pronounced peak of $280 \mathrm{~km}$ in Poland and also shows decreasing values from east to west with no distinct change in the gradient except a kind of plateau with about $180 \mathrm{~km}$ in northwestern Denmark. Except the decrease in lithospheric thickness from east to west, there is no other similar feature when compared to our GIA-model results.

The lithospheric thickness by Tesauro et al. (2009) reaches its highest value of $220 \mathrm{~km}$ in a broad band from southeastern Sweden to Latvia. It also shows decreasing values from east to west; however, the gradient is much steeper at the southwestern Swedish coast. It thins to $150 \mathrm{~km}$ towards the northwest of Denmark, and then becoming thicker again. To the north and south of this area values drop to less than $110 \mathrm{~km}$. There is a structural agreement in the form of the east-west decrease. The Rinkøping-Fyn High appears to lie further north in the thermal lithosphere. The thin GIA-lithosphere along the German Baltic Sea coast agrees with the plateau of $120 \mathrm{~km}$ in the thermal lithosphere. The structure of the Oslo Graben cannot be distinguished.

The best agreement of GIA-modelling-derived values is probably found in comparison to the new model by Priestley and McKenzie (2013). Both the EW-decrease trend and the location of the Rinkøping-Fyn High fit structurally well. Small differences are found in the northwest of our investigation area and in the German Bight. However, we also have to note that the spatial resolution of this model is two degrees and thus smaller features may not be clearly identified.

\section{Conclusions}

This is the first time that the regional earth structure in the southern Baltic Sea has been investigated with the help of regionally categorized RSL data and GIA modelling. Also, the lateral variation was visually compared to seismologically and/or thermally derived lithospheric thickness models 
for the first time. We employed the software ICEAGE and two different global ice models.

However, we made several assumptions and there are certain conditions to be kept in mind that may lead to different results in future investigations: we use ice models that are related to a certain earth model, and thus they are already biased by a certain lithospheric thickness and mantle viscosity. Our earth model is based on Maxwell rheology. Furthermore, it is possible that the ice models have imperfections that are absorbed by a wrong earth model, but anyhow lead to a good fit to the observations. We also note that variation in lithospheric thickness for regional subsets can only be clearly determined when mantle viscosity in each region is about constant (Kaufmann and Wu, 2002). This condition is not met for all regions. It is therefore possible that a 3-D earth model for the southern Baltic Sea with a different radial earth structure in each subregion than our determined 1-D earth models fits much better than a combination of all our 1-D models. All these items can increase the confidence regions of our study.

Within our calculated confidence levels, the following results were determined. The lithospheric thickness varies from $60 \mathrm{~km}$ in the Oslo Graben and the German Baltic Sea coast to up to $160 \mathrm{~km}$ in Poland. When only the best-fitting lithosphere is analysed, we see a trend to thicker lithosphere from west to east using the RSES ice model, but this is less pronounced with ICE-5G. The Rinkøping-Fyn High in between the Oslo Graben and Germany is at least $30 \mathrm{~km}$ thicker than the surrounding areas in the north and south. However, the confidence levels of the lithosphere are so large that an accurate determination is not possible. The variation in lithospheric thickness based on RSES agrees to a certain extent, when compared visually, to thickness models based on seismological and/or thermal investigation. A direct comparison of thicknesses is not possible due to the different definitions of lithosphere in seismological/thermal and GIA investigations.

Upper-mantle viscosity is about $[2-7] \times 10^{20} \mathrm{Pas}$ in the Oslo Graben and SW Sweden and thus confirms values found for Fennoscandia, the British Isles and the southern North Sea previously. In the southern Baltic Sea, similar values are obtained with ICE-5G, but we note quite high values of $2 \times 10^{21} \mathrm{~Pa}$ s for this region when using the RSES ice history. Bifurcation indicates that lower values in the range of [4-10] $\times 10^{20} \mathrm{~Pa}$ s are likely. As expected, lower-mantle viscosity cannot be sufficiently determined.

Future investigations with hopefully more RSL data in the southern Baltic Sea and an updated ice model (both tested ice models have experienced major recent improvements, but these revised versions have not been published yet) may help to further confirm the results herein with smaller confidence regions than ours and also overcome the differences between the results from the two ice models in certain areas. However, it will not be possible to add RSL data in the southern Baltic Sea which are older and deeper than the ones used in our study as the Pleistocene relief with the threshold of $25 \mathrm{~m}$ in the Great Belt did not allow an earlier deposition.

Acknowledgements. We are grateful for the excellent reviews by Wouter van der Wal and Patrick Wu that helped improve the paper. We would like to thank Kurt Lambeck (Research School of Earth Sciences, Australian National University) and Magdala Tesauro (GFZ Potsdam) for kindly providing the RSES ice model and the thermal lithosphere model in central and southern Europe, respectively. Figures were prepared using GMT software (Wessel and Smith, 1998).

Special Issue: "Lithosphere-cryosphere interactions"

Edited by: M. Poutanen, B. Vermeersen, V. Klemann, and C. Pascal

\section{References}

Artemieva, I. M.: The continental lithosphere: Reconciling thermal, seismic, and petrologic data, Lithos, 109, 23-46, doi:10.1016/j.lithos.2008.09.015, 2009.

Bennike, O., Jensen, J. B., Lemke, W., Kuijpers, A., and Lomholt, S.: Late- and postglacial history of the Great Belt, Denmark, Boreas, 33, 18-33, doi:10.1111/j.15023885.2004.tb00993.x,2004.

Bitinas, A., Damušyte, A., Hütt, G., Martma, T., Ruplenaite, G., Stančikaite, M., Úsaityte, D., and Vaikmäe, R.: Stratigraphic correlation of Late Weichselian and Holocene Deposits in the Lithuanian coastal region, P. Est. Acad. Sci.-Geol., 49, 200-217, 2000.

Bitinas, A., Damušyte, A., Stančikaite, M., and Aleksa P.: Geological development of the Nemunas River Delta and adjacent areas, West Lithuania, Geological Quarterly, 46, 375-389, 2002.

Christensen, Ch., Fischer, A., and Mathiassen, D. R.: The great sea rise in the Storebælt, in: The Danish Storebælt since the Ice Age - man, sea and forest, edited by: Pedersen, L., Fischer, A., and Aaby, B., A/S Storebælt Fixed Link, Copenhagen, 45-54, 1997.

Dèzes, P., and Ziegler, P. A.: Moho depth map of Western and Central Europe, avfailable at: https://comp1.geol.unibas.ch/, 2002.

Dziewonski, A. M. and Anderson D. L.: Preliminary reference Earth model, Phys. Earth Planet. Inter., 25, 297-356, doi:10.1016/0031-9201(81)90046-7, 1981.

Eaton, D. W., Darbyshire, F., Evans, R. L., Grütter, H., Jones, A. G., and Yuan, X.: The elusive lithosphereasthenosphere boundary (LAB) beneath cratons, Lithos, 109, 122, doi:10.1016/j.lithos.2008.05.009, 2009.

Farrell, W. E. and Clark, J. A.: On postglacial sea level, Geophys. J. R. Astr. Soc., 46, 647-667, doi:10.1111/j.1365246X.1976.tb01252.x, 1976.

Fjeldskaar, W.: Viscosity and thickness of the asthenosphere detected from the Fennoscandian uplift, Earth Planet. Sci. Lett., 126, 399-410, doi:10.1016/0012-821X(94)90120-1, 1994.

Geissler, W. H., Sodoudi, F., and Kind, R.: Thickness of the central and eastern european lithosphere as seen by $\mathrm{S}$ receiver functions, Geophys. J. Int., 181, 604-634, doi:10.1111/j.1365246X.2010.04548.x, 2010.

Gregersen, S., Voss, P., and the TOR Working Group: Summary of project TOR: delineation of a stepwise, sharp, deep lithosphere transition across Germany - Denmark - 
Sweden, Tectonophysics, 360, 61-73, doi:10.1016/S00401951(02)00347-5, 2002.

Hamza, V. M. and Vieira, F. P.: Global distribution of the lithosphere-asthenosphere boundary: a new look, Solid Earth, 3, 199-212, doi:10.5194/se-3-199-2012, 2012.

Hoffmann, G., Schmedemann, N., and Schafmeister, M.-Th.: Relative sea-level curve for SE Rügen and Usedom Island (SW Baltic Sea coast, Germany) using decompacted profiles, Z. dtsch. Ges. Geowiss., 160, 69-78, 2009.

Hofmann, W. and Winn, K.: The Littorina Transgression in the Western Baltic Sea as indicated by subfossil Chironomidae (Diptera) and Cladocera (Crustacea), Int. Rev. Hydrobiol., 85, 267-291, doi:10.1002/(SICI)15222632(200004)85:2/3<267::AID-IROH267>3.0.CO;2-Q, 2000.

Jakobsen, O.: Die Grube-Wesseker Niederung (Oldenburger Graben, Ostholstein): Quartärgeologische und geoarchäologische Untersuchungen zur Landschaftsgeschichte vor dem Hintergrund des anhaltenden postglazialen Meeresspiegelanstiegs, PhD.-Thesis, Univ. Kiel, 190 pp., 2004.

Kaufmann, G.: Program package ICEAGE, Version 2004, Manuscript, Institut für Geophysik der Universität Göttingen, 40 pp., 2004.

Kaufmann, G. and Wu, P.: Glacial isostatic adjustment in Fennoscandia with a three-dimensional viscosity structure as an inverse problem, Earth Planet. Sci. Lett., 197, 1-10, doi:10.1016/S0012-821X(02)00477-6, 2002.

Koulakov, I., Kaban, M. K., Tesauro, M., Cloetingh, S.: P and S velocity anomalies in the upper mantle beneath Europe from tomographic inversion of ISC data, Geophys. J. Int., 179, 345-366, doi:10.1111/j.1365-246X.2009.04279.x, 2009.

Lambeck K., Smither, C., and Johnston, P.: Sea-level change, glacial rebound and mantle viscosity for northern Europe, Geophys. J. Int., 134, 102-144, doi:10.1046/j.1365-246x.1998.00541.x, 1998.

Lampe, R., Meyer, H., Ziekur, R., Janke, W., and Endtmann, E.: Holocene evolution of an irregularly sinking coast and the interactions of sea-level rise, accumulation space and sediment supply, Bericht der Römisch-Germanischen Kommission, 88, 1546, 2007.

Lampe, R., Endtmann, E., Janke, W., and Meyer, H.: Relative sealevel development and isostasy along the NE German Baltic Sea coast during the past $9 \mathrm{ka}$, Quaternary Sci. J., 59, 3-20, doi:10.3285/eg.59.1-2.01, 2011.

Lange, W. and Menke, B.: Beiträge zur frühpostglazialen erdund vegetationsgeschichtlichen Entwicklung im Eidergebiet, insbesondere zur Flußgeschichte und zur Genese des sogenannten Basistorfes, Meyniana, 17, 29-44, 1967.

Lübke, H., Schmölcke, U., and Tauber, F.: Mesolithic HunterFishers in a Changing World: a case study of submerged sites on the Jäckelberg, Wismar Bay, northeastern Germany, in: Submerged Prehistory, edited by: Benjamin, J., Bonsall, C., Pickard, C., and Fischer, A., 21-37, Oxbow Books, Oxford, 2011.

Mitrovica, J. X., and Milne, G. A.: Glaciation-induced perturbations in the Earth's rotation: a new appraisal, J. Geophys. Res., 103, 985-1005, doi:10.1029/97JB02121, 1998.

Mitrovica, J. X., Davis, J. L., and Shapiro, I. I.: A spectral formalism for computing three-dimensional deformations due to surface loads 1. Theory, J. Geophys. Res., 99, 7057-7073, doi:10.1029/93JB03128, 1994.
Peltier, W. R.: Global glacial isostasy and the surface of the Ice-Age Earth: the ICE-5G (VM2) model and GRACE, Annu. Rev. Earth Pl. Sc., 32, 111-149, doi:10.1146/annurev.earth.32.082503.144359, 2004.

Petit, J. R., Jouzel, J., Raynaud, D., Barkov, N. I., Barnola, J. M., Basile, I., Bender, M., Chappellaz, J., Davis, J., Delaygue, G., Delmotte, M., Kotlyakov, V. M., Legrand, M., Lipenkov, V., Lorius, C., Pépin, L., Ritz, C., Saltzman, E., and Stievenard, M.: Climate and Atmospheric History of the Past 420,000 years from the Vostok Ice Core, Antarctica, Nature, 399, 429-436, doi:10.1038/20859, 1999.

Priestley, K. and McKenzie, D.: The relationship between shear wave velocity, temperature, attenuation and viscosity in the shallow part of the mantle, Earth Planet. Sci. Lett., 381, 78-91, doi:10.1016/j.eps1.2013.08.022, 2013.

Rößler, D., Moros, M., and Lemke, W.: The Littorina transgression in the southwestern Baltic Sea: new insights based on proxy methods and radiocarbon dating of sediment cores,, Boreas, 40, 231-241, doi:10.1111/j.1502-3885.2010.00180.x, 2011.

Scheck-Wenderoth, M., and Lamarche, J.: Crustal memory and basin evolution in the Central European Basin System - new insights from a 3D structural model, Tectonophysics, 397, 143165, doi:10.1016/j.tecto.2004.10.007, 2005.

Schmitt, L., Larsson, S., Burdukiewicz, J., Ziker, J., Svedhage, K., Zamon, J., Steffen, H.: Chronological insights, cultural change, and resource exploitation on the west coast of Sweden during the Late Paleolithic/early Mesolithic transition, Oxford J. Arch., 28, 1-27, doi:10.1111/j.1468-0092.2008.00317.x, 2009.

Steffen, H. and Kaufmann, G.: Glacial isostatic adjustment of Scandinavia and northwestern Europe and the radial viscosity structure of the Earth's mantle, Geophys. J. Int., 163, 801-812, doi:10.1111/j.1365-246X.2005.02740.x, 2005.

Steffen, H. and Wu, P.: Glacial isostatic adjustment in Fennoscandia - A review of data and modeling, J. Geodyn., 52, 169-204, doi:10.1016/j.jog.2011.03.002, 2011.

Steffen, H., Kaufmann, G., and Wu, P.: Three-dimensional finite-element modelling of the glacial isostatic adjustment in Fennoscandia, Earth Planet. Sci. Lett., 250, 358-375, doi:10.1016/j.eps1.2006.08.003, 2006.

Steffen, H., Wu, P., and Wang, H. S.: Determination of the Earth's structure in Fennoscandia from GRACE and implications on the optimal post-processing of GRACE data,Geophys. J. Int., 182, 1295-1310, doi:10.1111/j.1365-246X.2010.04718.x, 2010.

Tauber, F.: Seafloor exploration with sidescan sonar for geo-archaeological investigations, Berichte der RömischGermanischen Kommission, 88, 67-79, 2007.

Tesauro, M., Kaban, M. K., and Cloetingh, S. A. P. L.: A new thermal and rheological model of the European lithosphere, Tectonophysics, 476, 478-495, doi:10.1016/j.tecto.2009.07.022, 2009.

Uścinowicz, S.: Relative sea level changes, glacio-isostatic rebound and shoreline displacement in the Southern Baltic, Polish Geological Institute Special Papers, 10, 1-80, 2003.

van der Wal, W., Barnhoorn, A., Stocchi, P., Gradmann, S., Wu, P., Drury., M., and Vermeersen, L. L. A.: Glacial Isostatic Adjustment Model with Composite 3D Earth Rheology for Fennoscandia, Geophys. J. Int., 194, 61-77, doi:10.1093/gji/ggt099, 2013.

Vink, A., Steffen, H., Reinhardt L., and Kaufmann, G.: Holocene relative sea-level change, isostatic subsidence and the radial viscosity structure of the mantle of north-western Europe (Belgium, 
the Netherlands, Germany, southern North Sea), Quat. Sci. Rev., 26, 3249-3275, doi:10.1016/j.quascirev.2007.07.014, 2007.

Wang, H. S., Wu, P., and van der Wal, W.: Using postglacial sea level, crustal velocities and gravity-rate-of-change to constrain the influence of thermal effects on mantle lateral heterogeneities, J. Geodyn., 46, 104-117, doi:10.1016/j.jog.2008.03.003, 2008.

Wessel, P. and Smith, W. H. F.: New, improved version of generic mapping tools released, EOS Trans. AGU, 79, p. 579, doi:10.1029/98EO00426, 1998.

Winn, K., Averdieck, F.-R., Erlenkeuser, H. and Werner, F.: Holocene sea level rise in the western Baltic and the question of isostatic subsidence, Meyniana, 38, 61-80, 1986.
Wu, P., Wang, H. S., and Schotman, H.: Postglacial induced surface motions, sea levels and geoid rates on a spherical, selfgravitating laterally heterogeneous earth, J. Geodyn., 39, 127 142, doi:10.1016/j.jog.2004.08.006, 2005.

Wu, P., Wang, H., and Steffen, H.: The role of thermal effect on mantle seismic anomalies under Laurentia and Fennoscandia from observations of Glacial Isostatic Adjustment, Geophys. J. Int., 192, 7-17, doi:10.1093/gji/ggs009, 2013.

Yu, S.-Y., Berglund, B. E., Andrén, E., and Sandgren, P.: MidHolocene Baltic Sea transgression along the coast of Blekinge, SE Sweden - ancient lagoons correlated with beach ridges, GFF, 126, 257-272, doi:10.1080/11035890401263257, 2004. 